\title{
Perspectivas de Professores de Matemática sobre o Humor e o seu Valor Educacional
}

\section{Perspectives of Mathematics Teachers about Humour and its Educational Value}

\author{
Luís Menezes * \\ ORCID iD 0000-0002-8978-8900 \\ José António Fernandes ** \\ ORCID iD 0000-0003-2015-160X \\ Floriano Viseu $^{* * *}$ \\ ORCID iD 0000-0002-8221-6870 \\ António Ribeiro ${ }^{* * * *}$ \\ ORCID iD 0000-0001-9614-9552 \\ Pablo Flores ${ }^{* * * * *}$ \\ ORCID iD 0000-0002-3292-6639
}

\begin{abstract}
Resumo
O humor tem uma aceitação crescente, por se lhe reconhecer contributos positivos para o bem-estar das pessoas, em contextos como a saúde e as empresas. O que acontece na Educação, em particular, no ensino da Matemática? Na procura desta resposta, desenhamos este estudo, de natureza quantitativa, com uma amostra de 1088 professores de Matemática (portugueses e espanhóis). Com recurso a inquérito, averigua se professores que ensinam Matemática, ao longo dos diversos níveis de ensino, apreciam o humor, que perspectiva têm dele e do seu valor educativo e se o utilizam no ensino. O estudo averigua, ainda, se o nível de ensino em que lecionam tem influência na perceção e uso do humor com fins instrucionais. O estudo procura verificar se há diferenças significativas entre os professores portugueses e espanhóis em relação a estes aspectos. Os resultados revelam que a maioria dos professores, de todos os níveis de ensino, reconhecem o significado de humor, consideram que têm sentido de
\end{abstract}

\footnotetext{
* Doutor em Educaçãopela Universidade de Lisboa (UL). Professor Adjunto na Escola Superior de Educação do Instituto Politécnico de Viseu (IPV), Viseu, Portugal. Endereço para correspondência: Rua Maximiano Aragão, Viseu, Portugal, 3504-501. E-mail: menezes@esev.ipv.pt.

** Doutor em Educação pela Universidade do Minho (UM). Professor Associado no Instituto de Educação da Universidade do Minho (UM), Braga, Portugal. Endereço para correspondência: Campus de Gualtar, Braga, Portugal, 4710-057. E-mail: jfernandes@ie.uminho.pt.

*** Doutor em Educação pela Universidade de Lisboa (UL). Professor Auxiliar no Instituto de Educação da Universidade do Minho (UM), Braga, Portugal. Endereço para correspondência: Campus de Gualtar, Braga, Portugal, 4710-057. E-mail: fviseu@ie.uminho.pt.

**** Doutor em Didática pela Universidade de Aveiro (UA). Professor Adjunto na Escola Superior de Educação do Instituto Politécnico de Viseu (IPV), Viseu, Portugal. Endereço para correspondência: Rua Maximiano Aragão, Viseu, Portugal, 3504-501. E-mail: ribeiro@esev.ipv.pt.

***** Doutor em Matemáticas pela Universidade de Granada (UGR). Porofessor na Faculdade de Ciências da Educação da Univesidade de Granada (UGR), Granada, Espanha. Endereço para correspondência: Campus Universitario de Cartuja, Granada, Espanha, 18071. E-mail: pflores@ugr.es.
} 
humor, justificam o seu uso no ensino da Matemática e já o viram utilizar ou utilizam nas aulas, com o objetivo de criar bom ambiente de aprendizagem e de fazer pensar os alunos. O estudo revela diferenças entre os professores dos diversos níveis de ensino, indicando que existe maior predisposição dos professores dos Anos Iniciais, comparativamente com os demais, para valorizar e utilizar o humor no ensino. O estudo revela também diferenças entre professores portugueses e espanhóis, sendo os portugueses a apresentarem uma média de concordância superior na generalidade dos itens.

Palavras-chave: Humor. Ensino da Matemática. Perspectivas de Professores. Níveis de Ensino.

\begin{abstract}
At present, humour has an increasing acceptance and appreciation, because we recognize the positive contributions to the well-being of people in contexts as diverse as health, business, and entertainment. What happens in Education and, in particular, in Mathematics teaching? To answer this question, we designed this quantitative study with a sample of 1088 Iberian mathematics teachers (Portuguese and Spanish), that teach from the early years through to higher education. Through the use of a questionnaire, we seek to find out if Portuguese and Spanish teachers who teach Mathematics, throughout the various levels of education, appreciate humor, what perspective they have of it and its educational value, and if they use it in teaching the discipline. The study also sought to determine if the teaching level in which teachers teach mathematics has an influence on the perception and use of humor for instructional purposes. The study also investigates if there are any significant differences between Portuguese and Spanish teachers in relation to these aspects. The results show that the overwhelming majority of teachers, at all levels of teaching, recognize the meaning of humor, consider that they have a sense of humor, justify its use in mathematics teaching and have already seen it being used or used it in their classes, with the goal of creating a good learning environment and making students think. The study reveals differences among teachers at different levels of teaching, indicating that there is a greater predisposition of teachers in the initial years, in comparison to other years, to value and use humor in mathematics teaching. The study also reveals differences between Portuguese and Spanish teachers, with Portuguese presenting a higher average agreement in most items.
\end{abstract}

Keywords: Humor. Mathematics Teaching. Teachers perspectives. Teaching levels.

\title{
1 Introdução
}

O humor tem uma larga presença na sociedade atual, nos mais diversos campos de atividade, em contextos de lazer, como na internet e na televisão, mas também em contextos de trabalho, como na saúde (com fins terapêuticos) e na educação (com fins instrucionais) (DIONIGI; CANESTRARI, 2018; LAINESTE; VOOLAID, 2016; LOVORN; HOLAWAY, 2015; MEYER, 2015; NCTM, 2007, 2013).

Por definição, o humor é um ato comunicativo que recorre a mecanismos como a ambiguidade, a polissemia e a incongruência, com a intenção de bem dispor e fazer rir os outros (BANAS et al., 2011; MARTIN, 2007; MARTINS, 2015). É reconhecido que o humor joga com elementos cognitivos e emotivos, colocando, a quem o acolhe, desafios intelectuais tendo em vista a procura de significados que estão para além do denotativo, ou seja, o ato comunicativo humorístico coloca rasteiras à nossa razão e rimos quando nos apercebemos delas (BANAS et al., 2011; MARTIN, 2007). São estes elementos que fazem com que a generalidade das pessoas use e aprecie o humor. 
O humor facilita, pois, a comunicação e a sala de aula é um espaço comunicativo por excelência (GUERREIRO et al., 2015; MEYER, 2015; RODRIGUES; CYRINO; OLIVEIRA, 2018). Por isso, o humor pode ser visto como recurso educacional, um dos mais frequentemente estudados para facilitar o clima de sala de aula (BANAS et al., 2011). A mensagem humorística, em algumas formas de humor, como a que usa a incongruência, permite a introdução de situações de ruptura conceptual (FLORES; MORENO, 2011; MARTINS, 2015). Estas situações humorísticas envolvem, com frequência, a Matemática, gerando conflitos cognitivos que requerem, para a sua resolução, a apreciação de significados dos conceitos matemáticos utilizados, podendo redundar em aprendizagem da Matemática (FLORES; MORENO, 2011; NCTM, 2007, 2013; TOH et. al., 2017).

$\mathrm{Na}$ generalidade dos países do mundo, os professores que ensinam Matemática desde o Ensino Primário (EP) até ao Ensino Superior (ES) experienciam percursos formativos e de desenvolvimento profissional bastante distintos, tanto em termos de abrangência e profundidade da Matemática que estudam, como da importância que é dada à Didática da disciplina. Para além disso, estes professores ensinam alunos com idades e níveis de desenvolvimento muito díspares e conteúdos matemáticos que variam em termos de extensão, profundidade e forma de abordagem. Tendo em consideração todas estas diferenças, perguntamo-nos que papel atribuem os professores que ensinam Matemática, nos vários níveis de ensino, ao humor para ensinar Matemática e como o concretizam nas suas aulas? Para saber, procuramos responder às subquestões: O que é, para os professores que ensinam Matemática, o humor e o sentido do humor? Qual é, para eles, o valor didático do humor? Como é usado o humor nas práticas de sala de aula de Matemática?

É com estes pressupostos e questionamentos que avançamos para este estudo, num campo em que a investigação sobre o humor com fins educativos, tendo já algumas décadas, está muito confinada na aprendizagem e não no ensino e retrata fracamente o que se passa, a este nível, nas aulas de Matemática (BANAS et al., 2011). Estudamos professores portugueses e espanhóis, que, sendo vizinhos, partilham muitos valores culturais, fundamentais para a produção e compreensão do humor. Assim, é nosso objetivo averiguar se professores portugueses e espanhóis que ensinam Matemática, ao longo dos diversos níveis de ensino, apreciam o humor, que perspectiva têm dele e do seu valor educativo e se o utilizam no ensino. Procuramos, ainda, averiguar se o nível de ensino em que os professores ensinam Matemática tem influência nos diversos aspectos apontados anteriormente e se há diferenças significativas entre os professores portugueses e os espanhóis em relação a estes aspectos. 


\section{Fundamentação teórica}

Esta secção está organizada em dois pontos. No primeiro, discutimos os conceitos de humor e de sentido de humor, as suas formas e funções e as suas potencialidades educativas. No segundo ponto, focamos a formação dos professores que ensinam Matemática em Portugal e em Espanha.

\subsection{Humor no ensino da Matemática}

O humor é um processo comunicativo que tem como intenção fazer rir (BANAS et al., 2011; MEYER, 2015; WANZER et al., 2006). O humor e o riso, embora relacionados, constituem fenómenos diferentes. Enquanto o primeiro constitui um ato cognitivo que se expressa através da comunicação (oral, escrita ou gráfica), o segundo é um ato fisiológico de natureza reativa, que pode decorrer do humor e de muitos outros fenómenos como, por exemplo, a observação de situações ridículas e de comportamentos caricatos, mas, também, de situações de nervosismo e de stress (ADÃO, 2016; MARTINS, 2015; MEYER, 2015).

A comunicação humorística é, por natureza, subversiva, propondo formas alternativas de olhar para a realidade. Por isso, a mensagem humorística não pode ser interpretada literalmente, criando no público a quem se dirige a necessidade de pensar cuidadosamente para dar sentido àquilo que aparentemente é incongruente e contrário ao que se está a dizer (ADÃO, 2016; MARINS, 2015; MARTIN, 2007).

A produção, por um lado, e a perceção e apreciação do humor, por outro lado, constituem aquilo a que se chama de sentido de humor (ADÃO, 2016; MEYER, 2015). Esta capacidade cognitiva de apreciação do humor tem uma natureza multidimensional, acompanhando o desenvolvimento do ser humano ao longo da vida, sendo marcado pelas suas experiências pessoais e profissionais e, de modo mais global, pela cultura em que está inserido (ADÃO, 2016). Por isso, se há mensagens humorísticas que são interpretadas pela maioria das pessoas, porque remetem para experiências partilhadas pela generalidade delas, outras há que só são percebidas por grupos particulares de pessoas que possuem o conhecimento necessário para as compreender (MARTINS, 2015; MEYER, 2015).

A tentativa de compreender os mecanismos do humor tem suscitado o mais vivo interesse de numerosos autores, oriundos de múltiplos campos disciplinares, tais como a Literatura, a Filosofia, a História ou a Antropologia, e que remontam à Antiguidade Clássica, à Grécia Antiga, a pensadores como Platão, considerado o primeiro teórico do humor, que o concebia como divertimento linguístico (ADÃO, 2016; MARTINS, 2015). A teorização 
contemporânea do humor divide-se por três teorias principais: as Cognitivistas (Incongruência e Contraste); as Sociológicas (Hostilidade, Superioridade, Escárnio e Depreciação); e as Psicoanalíticas (Sublimação e Libertação) (MARTINS, 2015). No primeiro grupo, aquele que nos interessa neste estudo, o humor funciona na base da incongruência e do contraste entre ideias que aparentemente nenhuma relação têm entre si; o humor opera-se quando a razão encontra a conexão entre essas ideias. Uma tira muito conhecida de Mafalda, de Quino, expressa bem este mecanismo. Na primeira vinheta, uma professora desenha um pentágono no quadro e diz: "Bem, hoje vamos estudar o pentágono". Na segunda vinheta, Mafalda, uma das alunas da classe, tem uma intervenção incongruente, que parece não fazer sentido: "E amanhã, o Kremlin?” Na vinheta final, Mafalda conclui: “Quer dizer, para equilibrar”. A resolução desta incongruência pode conduzir o leitor ao riso (ADÃO, 2016; MARTINS, 2015). As teorias Sociológicas explicam o humor através da superioridade, do escárnio e da depreciação. Este mecanismo está presente em grande parte do humor político e de costumes, quando se escarnece e depreciam atos das pessoas, e também nas anedotas que, habitualmente, as pessoas de um país contam das pessoas dos países vizinhos. Este tipo de humor, que pressupõe alguma crítica, nem sempre é bem recebido pelos visados, podendo gerar reações adversas (MARTINS, 2015). Por último, as teorias Psicoanalíticas explicam o humor por mecanismos de sublimação e libertação, permitindo que as pessoas, pelo riso, resolvam situações de tensão, muitas vezes associadas a proibições (ADÃO, 2016; MARTINS, 2015).

Um outro aspecto importante do estudo do humor prende-se com as suas funções para além daquela que parece ser a mais evidente, entreter e bem dispor as pessoas em situações de lazer. A investigação tem revelado outras funções como a promoção da produtividade em empresas, o uso terapêutico e o uso educativo (DIONIGI; CANESTRARI, 2018; LAINESTE; VOOLAID, 2016; MARTIN, 2007; MEYER, 2015). No presente estudo, interessam-nos as utilizações do humor no ensino, em particular no da Matemática.

O estudo do uso do humor com fins instrucionais, em diversas disciplinas escolares, realizado nas últimas cinco décadas foi revisto por diversos autores (ADÃO, 2016; BANAS et al., 2011; GUITART, 2012; MARTIN, 2007). Estes estudos, essencialmente de natureza quantitativa, revelam que: "o uso do humor é um comportamento predominante na comunicação em ambientes pedagógicos e serve para diferentes propósitos" (BANAS et al., 2011, p. 137); o humor tem resultados positivos na criação de ambientes que facilitam a aprendizagem, estando "relacionado positivamente com um ambiente de aprendizagem agradável" (BANAS et al., 2011, p. 130); o humor aumenta a capacidade de concentração dos alunos; o humor ajuda a aprender conceitos que habitualmente produzem mais dificuldades nos 
alunos, pois "o uso de humor instrucional para aliviar a tensão pode ser especialmente útil para o ensino de tópicos que, em geral, são percebidos pelos alunos como provocadores de ansiedade" (BANAS et al., 2011, p. 130); o uso do humor em situações de avaliação ajuda a diminuir o stress que muitas vezes está associado a estes momentos. Outros estudos realizados nos últimos anos olham para o humor, usado pelos professores, para promover a aprendizagem, da perspectiva dos alunos (MACHLEV; KARLIN, 2017; WANZER et al., 2006). Estes estudos pretendem que os estudantes, a frequentar cursos superiores, recordem utilizações do humor pelos seus professores, identificando usos apropriados e não apropriados para a sua aprendizagem. Destes estudos, emerge que os alunos identificam como relevante e com impacto na sua aprendizagem aquele humor que incide diretamente sobre os conteúdos do curso.

A utilização do humor no ensino da Matemática tem já alguma tradição (GUITART, 2012; MATARAZZO; DURIK; DELANEY, 2010; SHMAKOV; HANNULA, 2010), especialmente aquela que tira partido de suportes gráficos, como banda desenhada e cartoons (FLORES; MORENO, 2011; GUITART, 2012; NCTM, 2007, 2013). O estudo de Guitart (2012) foca o uso do humor no ensino da Estatística num curso superior. Para isso, realiza uma investigação-ação estudando o impacto na aprendizagem da Estatística em resultado da utilização de situações humorísticas no seu ensino. O estudo conclui que o humor teve um impacto importante na realização de aprendizagens significativas dos conceitos estatísticos.

Alguns destes estudos, apesar de apresentarem relatos de sala de aula e materiais para o ensino da disciplina de Matemática, apresentam um quadro pouco completo sobre o que pensam os professores que ensinam Matemática sobre o humor e o seu valor instrucional. É neste nicho que este estudo se insere, focando os professores que ensinam Matemática desde os Anos Iniciais até ao Ensino Superior.

\subsection{Formação de professores de Matemática em Portugal e Espanha}

Quem são os professores que ensinam Matemática em Portugal e Espanha? A resposta a esta pergunta, baseada nos normativos legais (CASTRO; FLORES, 2012; PORTUGAL, 2014), revela, nos dois países, realidades com algumas semelhanças ao longo dos diversos anos de escolaridade. Em Espanha, a escolaridade obrigatória abrange alunos de 6 a 16 anos, em dois ciclos, o Ensino Primário (6 anos de escolaridade) e o Ensino Secundário (quatro anos, dos 12 aos 16 anos de idade). O 'bachillerato' é um ciclo de ensino preparatório para a universidade (dois anos, dos 17 aos 18 anos de idade).

Em Portugal, a escolaridade obrigatória é de 12 anos, dividindo-se em Ensino Básico (9 
anos, em 3 ciclos, dos 6 aos 15 anos) e Ensino Secundário (3 anos, dos 16 aos 18 anos). Os professores dos Anos Iniciais são generalistas, ensinando diversas disciplinas (em Espanha, os primeiros 6 anos, e em Portugal, os primeiros 4 anos). A partir daí, em ambos os países, há professores especialistas que ensinam Matemática.

Em Espanha, os professores do Ensino Primário realizam uma licenciatura em Ensino Primário, com 240 créditos (um crédito corresponde, aproximadamente, a 25h de trabalho dos alunos), abrangendo formação em didática geral, formação em didáticas específicas e prática pedagógica. O número de créditos da área da Matemática varia entre 8 e $10 \%$ dos créditos do curso. Em Portugal, os professores dos Anos Iniciais ( $1^{\circ}$ e $2^{\circ}$ ciclos do Ensino Básico) realizam uma graduação inicial de 3 anos (180 créditos) e depois um mestrado profissionalizante (120 créditos), abrangendo áreas da docência, formação educacional geral, expressões e iniciação à prática profissional. O número de créditos da área da Matemática é $18 \%$ dos créditos do curso. No mestrado, os estudantes completam a sua formação matemática com um número de créditos que varia entre 8 e $10 \%$ dos créditos do curso.

Em Espanha, os professores de Matemática do Ensino Secundário são licenciados em Ciências (190 créditos), de preferência em Matemática, que, depois, concluem um mestrado profissional de formação específica (60 créditos). Em Portugal, os professores do $3^{\circ}$ ciclo do Ensino Básico e do Ensino Secundário obtêm a sua formação através de uma licenciatura em Matemáica (120 créditos), seguida de mestrado profissionalizante (120 créditos). Tanto num caso como noutro, as licenciaturas têm grande peso de Matemática, aparecendo as didáticas, formação educacional geral e prática pedagógica no mestrado.

Tanto em Portugal como na Espanha, os professores de Matemática do Ensino Superior fazem, em regra, sucessivamente, licenciatura, mestrado e doutoramento em Matemática, não tendo, em muitos casos, nenhuma formação na área das didáticas ou estágio profissional.

\section{Metodologia}

Esta secção está organizada em três pontos. No primeiro, apresentamos as opções metodológicas e o instrumento de recolha de dados. No segundo, descrevemos os participantes no estudo. No último, explicamos como se processa a análise de dados.

\subsection{Opções metodológicas e instrumento}

O estudo adotou uma abordagem quantitativa no tratamento da informação resultante 
das respostas dos professores participantes ao questionário elaborado, tendo em vista descrever e interpretar essa informação (GALL; GALL; BORG, 2003). Para além de itens destinados à caraterização dos participantes, o questionário utilizado nesta pesquisa é organizado em torno de três dimensões de análise: 1) Humor e sentido de humor; 2) Valor educativo do humor no ensino e na aprendizagem da Matemática; e 3) O uso do humor no ensino da Matemática.

Por sua vez, a primeira dimensão integra cinco subdimensões: Significado do humor, com seis itens; Sentido do humor, com cinco itens; Sentido do humor nos outros, com quatro itens; Assuntos do humor, com quatro itens; e Fontes do humor, com cinco itens. A segunda dimensão apresenta quatro subdimensões: Compatibilidade do humor com o ensino da Matemática, com cinco itens; Uso do humor no ensino de temas matemáticos, com cinco itens; Recursos de promoção do humor, com quatro itens; e Suportes do uso do humor, com cinco itens. E, finalmente, a terceira dimensão é estruturada por duas subdimensões: Finalidade do uso do humor pelo professor de Matemática enquanto aluno, com quatro itens; e Finalidade do uso do humor no ensino da Matemática, com quatro itens. A opção por apresentar itens fechados deveu-se ao facto de serem questões de resposta fácil e rápida para os professores. Assim, para responder a cada uma das questões, os professores teriam que selecionar uma opção de concordância de 1 a 4, considerando que 1 corresponde ao valor mínimo e que 4 corresponde ao valor máximo. A partir das respostas dos professores, determinou-se a média destes valores em cada item.

\subsection{Participantes no estudo}

Para a seleção da amostra, enviou-se o questionário para escolas (dos Ensinos Básico, Secundário e Superior) e associações profissionais de professores de Matemática, de Portugal e de Espanha. O método de amostragem foi o de conveniência (GALL; GALL; BORG, 2003; HILL; WILLIAMS, 2012), tendo os questionários sido distribuídos, via email, em várias escolas de todos os níveis de ensino e associações profissionais de professores de Matemática. Esta abordagem metodológica, comum em investigação em Educação (GALL; GALL; BORG, 2003), é motivada, fundamentalmente, por condicionamentos ao nível de recursos.

Participaram no estudo 1088 professores de Matemática (portugueses e espanhóis), cuja idade variava entre os 23 e os 67 anos, com média de idades de, aproximadamente, 47 anos. Em termos de experiência de ensino, em média, o tempo de serviço era de 21 anos, havendo professores em início de carreira (com 0 anos de serviço) e professores com 49 anos de serviço. Entre os professores que indicaram o género, $69,8 \%$ afirmaram ser do género feminino e 30,2\% 
do género masculino. Quanto à nacionalidade dos professores, 595 eram portugueses $(54,7 \%)$ e os outros 493 eram espanhóis (45,3\%). Quanto ao nível de ensino em que lecionavam, os professores, exceto dois que não indicaram o nível em que lecionavam, foram distribuídos por três grupos, assim designados neste estudo: Ensino Primário (EP), incluindo professores que ensinavam desde o $1^{\circ}$ ao $6^{\circ}$ ano de escolaridade, num total de 375 (34,5\%); Ensino Médio (EM), incluindo professores que ensinavam desde o $7^{\circ}$ ao $9^{\circ}$ ano, num total de 635 (58,5\%); e Ensino Superior (ES), incluindo professores que ensinavam depois do $12^{\circ}$ ano, em instituições de Ensino Superior, num total de 76 professores (7\%).

\subsection{Análise de dados}

A análise de dados, num estudo quantitativo, realiza-se por meio de métodos estandardizados, objetivos e relativamente bem estabelecidos, que não requerem uma descrição muito detalhada. No presente estudo, a análise de dados se desenvolveu em dois níveis: a um nível descritivo e a um nível indutivo (GALL; GALL; BORG, 2003; PESTANA; GAGEIRO, 2008). No nível descritivo, determinaram-se as médias dos graus de concordância manifestados pelos professores segundo cada um dos três grupos correspondentes aos níveis de ensino considerados, o que permitiu comparar esses grupos em cada item de cada subdimensão préestabelecida e na totalidade do questinário.

Em seguida, no nível indutivo, comparamos as médias de concordância dos três grupos em cada item através da análise de variância One-Way Anova. No caso de a análise de variância determinar diferenças estatisticamente significativas entre os grupos, prosseguiu-se a análise com o estudo das comparações múltiplas entre quaisquer dois grupos, recorrendo ao teste de Bonferroni. Ainda a nível indutivo, recorrendo ao teste $\mathrm{t}$ de Student para amostras independentes, compararam-se as médias de concordância entre os professores portugueses e os espanhóis em cada item e na totalidade do questionário. $\mathrm{Na}$ análise estatística, com recurso ao software SPSS, versão 23 para Windows, consideramos o valor 0,05 para nível de significância estatística e, sempre que se recorreu a testes estatísticos, teve-se sempre em consideração a verificação das condições requeridas para a sua aplicação.

\section{Resultados}

Esta seção está organizada em quatro pontos. Nos três primeiros, analisam-se as três dimensões incluídas no questionário: "Humor e sentido de humor"; "Valor educativo do humor 
no ensino e na aprendizagem da Matemática"; e "O uso do humor no ensino da Matemática". No quarto e último ponto, intitulado "O humor em Matemática", analisam-se as respostas dos professores aos itens do questionário envolvendo a própria experiência dos professores participantes.

\subsection{Humor e sentido de humor}

Na indagação sobre o que é o humor, as respostas dos professores distribuíram-se pelos variados atributos que eram especificados no questionário, conforme se pode verificar na Tabela 1. De entre esses atributos, destacam-se a sua contribuição para 'aliviar a tensão/ansiedade', 'estimular o pensamento', 'descontrair' e 'melhorar a autoestima'. Além disso, globalmente, são os professores do EP que apresentam uma maior média de concordância nos diferentes atributos considerados.

Tabela 1 - Média da concordância dos professores e valor de p nos itens sobre o que é o humor, segundo o nível de ensino

\begin{tabular}{lcccc}
\hline \multirow{2}{*}{ Para mim, o humor é qualquer situação que: } & \multicolumn{3}{c}{ Média segundo o nível de ensino } & \multirow{2}{*}{ Valor de $\mathrm{p}$} \\
\cline { 2 - 4 } & Primário & Médio & Superior & \\
\hline Provoque o riso & 3,02 & 2,92 & 2,93 & 0,100 \\
Descontraia & 3,43 & 3,00 & 2,90 & $0,000^{*}$ \\
Ajude a lidar com perdas, desgostos ou desilusões & 2,85 & 2,72 & 2,58 & $0,003^{*}$ \\
Estimule o pensamento & 3,49 & 3,20 & 3,26 & $0,000^{*}$ \\
Ajude a aliviar a tensão/ansiedade & 3,55 & 3,32 & 3,33 & $0,000^{*}$ \\
Contribua para melhorar a autoestima & 3,40 & 3,12 & 2,85 & $0,000^{*}$ \\
\hline
\end{tabular}

${ }^{*}$ Diferenças estatisticamente significativas para $p<0,05$.

Fonte: Elaboração dos autores (2019).

Comparando as médias dos três níveis de ensino através do One-Way Anova, verificase que existem diferenças significativas em cinco dos seis itens. Nestes itens, relativos aos atributos 'descontrair', 'ajudar a lidar com perdas, desgostos ou desilusões', 'estimular o pensamento', 'aliviar a tensão/ansiedade' e 'melhorar a autoestima', observaram-se diferenças significativas entre os professores do EP e os professores de qualquer dos outros dois grupos.

Destes itens, à exceção do item ‘ajudar a lidar com perdas, desgostos ou desilusões', em todos os restantes observaram-se diferenças significativas entre os professores portugueses e espanhóis, sempre com uma média de concordância superior para os portugueses.

A maioria dos professores $(89,8 \%$ ) considera-se uma pessoa com sentido de humor, com maior prevalência nos professores do EP, o que se expressa através de 'situações ou histórias engraçadas', com a finalidade de alivar 'a tensão', desafiar 'os outros a pensar' e fazer r'as pessoas ir' (Tabela 2). 
Tabela 2 - Média da concordância dos professores e valor de p nos itens sobre o seu sentido de humor, segundo o nível de ensino

\begin{tabular}{lcccc}
\hline \multirow{2}{*}{ Considero-me uma pessoa com sentido de humor porque: } & \multicolumn{4}{c}{ Média segundo o nível de ensino } \\
\cline { 2 - 4 } & Primário & Médio & Superior & \\
\hline Eu consigo dizer as coisas de um modo que faz as pessoas rir & 2,94 & 2,80 & 2,68 & $0,000^{*}$ \\
As pessoas esperam que diga coisas engraçadas & 2,52 & 2,26 & 2,25 & $0,000^{*}$ \\
Às vezes, vêm-me à cabeça situações ou histórias engraçadas & 3,12 & 2,92 & 3,08 & $0,000^{*}$ \\
Através de expressões engraçadas, ponho os outros a pensar & 2,94 & 2,81 & 2,91 & $0,019^{*}$ \\
$\begin{array}{l}\text { Eu consigo aliviar uma situação de tensão dizendo algo } \\
\text { engraçado }\end{array}$ & 2,90 & 2,84 & 2,94 & 0,311 \\
\hline
\end{tabular}

${ }^{*}$ Diferenças estatisticamente significativas para $p<0,05$.

Fonte: Elaboração dos autores (2019).

Comparando as médias dos três níveis de ensino, verifica-se que existem diferenças significativas em quatro dos cinco itens. Em dois desses itens, relativos aos atributos 'faz as pessoas rir' e 'diga coisas engraçadas', observam-se diferenças significativas entre os professores do EP e os professores dos outros dois níveis de ensino. Nos outros dois itens, relativos aos atributos surgir na mente 'situações ou histórias engraçadas' e recorrer a 'ponho os outros a pensar', existem diferenças significativas entre os professores do EP e os professores do EM.

Dos itens anteriores, excetuando o item 'ponho os outros a pensar', observaram-se diferenças significativas entre os professores portugueses e espanhóis nos restantes três itens, verificando-se novamente uma média de concordância superior no caso dos portugueses.

Para além da predisposição de cultivarem momentos de graciosidade, a quase totalidade dos professores $(99,5 \%)$, com ligeiro destaque para os do EP, aprecia o sentido de humor nos outros, por ajudar a 'gerir situações difíceis', 'sentir-se mais à vontade e descontraído', 'adaptar-se a situações do quotidiano' e 'ser mais produtivo no trabalho' (Tabela 3).

Tabela 3 - Média da concordância dos professores e valor de $\mathrm{p}$ nos itens sobre o sentido de humor nos outros, segundo o nível de ensino

\begin{tabular}{lcccc}
\hline \multirow{2}{*}{ Aprecio o sentido de humor nos outros porque: } & \multicolumn{3}{c}{ Média segundo o nível de ensino } \\
\cline { 2 - 4 } Valor de $\mathrm{p}$ \\
\hline O humor dos outros ajuda-me a sentir mais à vontade e & 3,49 & 3,32 & 3,47 & $0,000^{*}$ \\
$\begin{array}{l}\text { descontraído } \\
\text { Humor inteligente ajuda-me a gerir situações difíceis }\end{array}$ & 3,51 & 3,36 & 3,39 & $0,001^{*}$ \\
$\begin{array}{l}\text { Lidar com as situações do quotidiano recorrendo ao humor } \\
\text { é uma forma de me adaptar melhor a elas }\end{array}$ & 3,31 & 3,24 & 3,28 & 0,193 \\
Usar o humor ajuda-me a ser mais produtivo no trabalho & 3,24 & 3,13 & 3,04 & $0,012^{*}$ \\
\hline
\end{tabular}

${ }^{*}$ Diferenças estatisticamente significativas para $p<0,05$.

Fonte: Elaboração dos autores (2019).

Entre as médias dos três níveis de ensino, verifica-se que existem diferenças significativas em três dos quatro itens. Desses itens, relativos aos atributos ajudar a 'sentir mais à vontade e descontraído', 'gerir situações difíceis' e ser 'mais produtivo no trabalho', 
constataram-se diferenças significativas entre os professores do EP e os professores do EM.

Agora, entre os professores portugueses e espanhóis, verificaram-se diferenças significativas nos três itens antes referidos, sendo novamente os portugueses a apresentarem uma média de concordância superior.

Interpelados sobre possíveis assuntos em que apreciam o humor, os professores do EP destacam mais os assuntos de 'Política' e 'Desporto', enquanto os professores do ES destacam aquele que diz respeito a 'Usos e costumes' (Tabela 4).

Tabela 4 - Média da concordância dos professores e valor de p nos itens sobre os assuntos em que apreciam o humor, segundo o nível de ensino

\begin{tabular}{lccccc}
\hline \multirow{2}{*}{ Aprecio o humor sobre: } & \multicolumn{3}{c}{ Média segundo o nível de ensino } & \multirow{2}{*}{ Valor de $\mathrm{p}$} \\
\cline { 2 - 4 } & Primário & Médio & Superior & $0,000^{*}$ \\
\hline Política & 3,03 & 2,65 & 2,95 & 0,946 \\
Usos e costumes & 3,27 & 3,27 & 3,30 & $0,000^{*}$ \\
Desporto & 2,94 & 2,62 & 2,46 & 0,416 \\
Educação & 3,20 & 3,14 & 3,20 & \\
\hline
\end{tabular}

${ }^{*}$ Diferenças estatisticamente significativas para $p<0,05$.

Fonte: Elaboração dos autores (2019).

Comparando as médias dos três níveis de ensino, verifica-se que existem diferenças significativas em dois dos quatro itens, relativos aos atributos apreciar humor em assuntos de 'Política' e de 'Desporto'. No primeiro item observaram-se diferenças significativas entre os professores do EP e os professores do EM, enquanto no outro item se observaram diferenças significativas entre os professores do EP e os professores de qualquer dos outros dois níveis de ensino.

Também neste caso, entre os professores portugueses e espanhóis, se verificaram diferenças significativas nos dois itens antes referidos, sendo novamente os portugueses a apresentarem uma média de concordância superior.

$\mathrm{Na}$ procura de assuntos de humor, os professores recorrem a diferentes fontes. Neste caso, os professores de todos os níveis de ensino concordam mais em procurar o humor em 'Grupos de amigos', destacando-se também a 'Televisão' e o ‘Cinema' nos professores do EP e a 'Internet' nos professores do EM e do ES (Tabela 5). 
Tabela 5 - Média da concordância dos professores e valor de p nos itens sobre as fontes de humor, segundo o nível de ensino

\begin{tabular}{lccccc}
\hline \multirow{2}{*}{ Procuro o humor em: } & \multicolumn{3}{c}{ Média segundo o nível de ensino } & \multirow{2}{*}{ Valor de p } \\
\cline { 2 - 4 } & Primário & Médio & Superior & \\
\hline Televisão & 3,01 & 2,63 & 2,71 & $0,000^{*}$ \\
Cinema & 2,90 & 2,71 & 2,72 & $0,001^{*}$ \\
Revistas & 2,39 & 2,18 & 2,16 & $0,001^{*}$ \\
Internet & 2,83 & 2,90 & 2,87 & 0,590 \\
Grupos de amigos & 3,53 & 3,41 & 3,46 & $0,008^{*}$ \\
\hline
\end{tabular}

${ }^{*}$ Diferenças estatisticamente significativas para $p<0,05$.

Fonte: Elaboração dos autores (2019).

Entre as médias dos três níveis de ensino, verifica-se que existem diferenças significativas em quatro dos cinco itens. No item relativo à 'Televisão' observaram-se diferenças significativas entre os professores do EP e os professores de qualquer dos outros dois níveis de ensino. Já nos itens relativos ao 'Cinema', 'Revistas' e 'Grupos de amigos', verificaram-se diferenças significativas entre os professores do EP e os professores do EM.

De todos os cinco itens, apenas não se verificaram diferenças significativas entre os professores portugueses e espanhóis no item 'Grupos de amigos'. Nestes itens, obteve-se uma média de concordância superior para os professores espanhóis no item 'Internet' e para os professores portugueses nos três outros itens.

\subsection{Valor educativo do humor no ensino e na aprendizagem da Matemática}

Apesar dos objetos matemáticos serem de natureza abstrata, o que favorece a perceção de uma disciplina exata, de elevada complexidade cognitiva e séria, quase todos os professores consideram que o ensino de Matemática é compatível com o recurso ao humor (98\%). Também neste caso, os professores do EP se destacam dos demais quanto ao nível de concordância que atribuem a essa compatibilidade, ao facilitar 'a relação pedagógica entre o professor e os alunos', ao tornar 'a Matemática mais atrativa', ao estimular 'o pensamento matemático' e ao facilitar 'a comunicação matemática' (Tabela 6). Já os professores do ES destacam-se ligeiramente dos restantes níveis de ensino ao concordarem que 'as aulas de Matemática com humor são mais agradáveis'.

Tabela 6 - Média da concordância dos professores e valor de p nos itens sobre a compatibilidade do humor com o ensino da Matemática, segundo o nível de ensino

\begin{tabular}{lcccc}
\hline \multirow{2}{*}{$\begin{array}{l}\text { O ensino da Matemática é compatível com o recurso ao humor } \\
\text { porque: }\end{array}$} & \multicolumn{3}{c}{ Média segundo o nível de ensino } & Valor de $\mathrm{p}$ \\
\cline { 2 - 5 } & Primário & Médio & Superior & \\
\hline As aulas de Matemática com humor são mais agradáveis & 3,51 & 3,50 & 3,53 & 0,915 \\
O humor estimula o pensamento matemático & 3,38 & 3,15 & 3,14 & $0,000^{*}$ \\
O humor facilita a comunicação matemática & 3,37 & 3,19 & 3,31 & $0,000^{*}$ \\
O humor torna a Matemática mais atrativa & 3,57 & 3,41 & 3,29 & $0,000^{*}$
\end{tabular}


$\begin{array}{llllll}\text { O humor facilita a relação pedagógica entre professor e alunos } & 3,67 & 3,58 & 3,59 & 0,028^{*}\end{array}$ ${ }^{*}$ Diferenças estatisticamente significativas para $p<0,05$.

Fonte: Elaboração dos autores (2019).

A aplicação da análise de variância One-Way Anova determinou diferenças significativas entre as médias dos três níveis de ensino em quatro dos cinco itens. Nos itens relativos aos atributos 'estimular o pensamento matemático' e 'tornar a Matemática mais atrativa' observaram-se diferenças significativas entre os professores do EP e os professores de qualquer dos outros dois níveis de ensino. Nos outros dois itens, relativos aos atributos 'facilitar a comunicação matemática' e 'facilitar a relação pedagógica entre professor e alunos', observaram-se diferenças significativas entre os professores do EP e os professores do EM.

Excetuando o item 'facilitar a relação pedagógica entre professor e alunos', em todos os outros itens verificaram-se diferenças significativas entre os professores portugueses e espanhóis. Nestes itens, obteve-se uma média de concordância superior para os professores espanhóis no item 'As aulas de Matemática com humor são mais agradáveis' e para os professores portugueses nos outros três itens.

A compatibilidade do humor com o ensino de Matemática é afirmada pelos professores, destacando os do EP a referirem a sua utilização no ensino de tópicos de 'Geometria' e de 'Álgebra', enquanto os professores do ES destacam essa utilização no ensino de 'Probabilidades', 'Estatística' e 'Números e operações' (Tabela 7).

Tabela 7 - Média da concordância dos professores e valor de p nos itens sobre o uso do humor no ensino de diferentes temas matemáticos, segundo o nível de ensino

\begin{tabular}{lcccc}
\hline Aprecie, relativamente a cada um dos seguintes temas, a & \multicolumn{3}{c}{ Média segundo o nível de ensino } & \multirow{2}{*}{ Valor de $\mathrm{p}$} \\
\cline { 2 - 5 } possibilidade de utilizar situações humorísticas no ensino de: & Primário & Médio & Superior & \\
\hline Geometria & 3,06 & 2,96 & 3,04 & 0,098 \\
Estatística & 3,30 & 3,36 & 3,49 & 0,097 \\
Probabilidades & 3,36 & 3,39 & 3,55 & 0,083 \\
Álgebra & 2,86 & 2,65 & 2,82 & $0,000^{*}$ \\
Números e operações & 3,11 & 2,82 & 3,19 & $0,000^{*}$ \\
\hline
\end{tabular}

${ }^{*}$ Diferenças estatisticamente significativas para $p<0,05$.

Fonte: Elaboração dos autores (2019).

Comparando as médias dos três níveis de ensino, verifica-se que existem diferenças significativas em dois dos cinco itens. Nestes itens, relativos aos atributos utilizar situações humorísticas no ensino de 'Álgebra' e de 'Números e operações', observaram-se diferenças significativas entre os professores do EP e os do EM.

De entre os itens, observaram-se diferenças significativas entre os professores portugueses e espanhóis apenas no item 'Números e operações', tendo sido os portugueses a apresentarem uma média de concordância superior.

A utilização do humor na aula de Matemática pode realizar-se através de vários recursos, 
entre os quais os professores do Ensino Superior destacam as 'Fichas de trabalho' e os professores do EP apontam as 'Apresentações em PowerPoint', o 'Manual escolar' e os 'Testes' (Tabela 8).

Tabela 8 - Média da concordância dos professores e valor de p nos itens sobre o uso de recursos para promover o humor na aula de Matemática, segundo o nível de ensino

\begin{tabular}{|c|c|c|c|c|}
\hline \multirow{2}{*}{$\begin{array}{l}\text { Para cada um dos seguintes recursos, aprecie a sua adequação } \\
\text { para utilizar o humor na aula de Matemática }\end{array}$} & \multicolumn{3}{|c|}{ Média segundo o nível de ensino } & \multirow{2}{*}{ Valor de $\mathrm{p}$} \\
\hline & Primário & Médio & Superior & \\
\hline Fichas de trabalho & 2,51 & 2,47 & 2,54 & 0,631 \\
\hline Manual escolar & 2,55 & 2,29 & 2,36 & $0,000 *$ \\
\hline Testes & 2,08 & 1,98 & 1,92 & 0,086 \\
\hline Apresentacões em PowerPoint & 3,33 & 3,05 & 3,23 & $0,000 *$ \\
\hline
\end{tabular}

${ }^{*}$ Diferenças estatisticamente significativas para $p<0,05$.

Fonte: Elaboração dos autores (2019).

Entre as médias dos três níveis de ensino, verifica-se que existem diferenças significativas em dois dos quatro itens, relativos aos atributos utilizar o 'Manual escolar' e 'Apresentações em PowerPoint', sendo essas diferenças significativas entre os professores do EP e os professores do EM.

Também nestes dois itens se observaram diferenças significativas entre os professores portugueses e espanhóis, sendo novamente os portugueses a apresentaram uma média de concordância superior.

Entre os suportes que permitem a introdução de situações humorísticas no ensino da Matemática, os professores do ES destacam os 'Cartoons', a 'Banda desenhada', o 'Discurso oral do professor' e o 'Texto escrito', enquanto o 'Vídeo' é mais destacado pelos professores do EP (Tabela 9).

Tabela 9 - Média da concordância dos professores e valor de $\mathrm{p}$ nos itens sobre o uso de diferentes suportes para promover o humor no ensino da Matemática, segundo o nível de ensino

\begin{tabular}{lcccc}
\hline Para cada um dos seguintes suportes, aprecie a sua adequação & \multicolumn{3}{c}{ Média segundo o nível de ensino } \\
\cline { 3 - 5 } $\begin{array}{l}\text { para a introdução de situações humorísticas no ensino da } \\
\text { Matemática }\end{array}$ & Primário & Médio & \multirow{2}{*}{ Superior } & \\
\hline Cartoons & 3,32 & 3,16 & 3,51 & $0,000^{*}$ \\
Banda desenhada & 3,34 & 3,07 & 3,44 & $0,000^{*}$ \\
Vídeo & 3,28 & 3,11 & 3,21 & $0,004^{*}$ \\
Texto escrito & 2,77 & 2,68 & 2,85 & 0,065 \\
Discurso oral do professor & 3,43 & 3,38 & 3,49 & 0,289 \\
\hline
\end{tabular}

${ }^{*}$ Diferenças estatisticamente significativas para $p<0,05$.

Fonte: Elaboração dos autores (2019).

Comparando as médias dos três níveis de ensino, verifica-se que existem diferenças significativas em três dos cinco itens. Nos itens relativos ao uso de 'Cartoons' e 'Banda desenhada' observaram-se diferenças significativas quer entre os professores do EP e os professores do EM, quer entre os professores do ES e os professores do EM. No caso do uso do 
'Vídeo', observaram-se diferenças significativas entre os professores do EP e os do EM.

Em dois dos três itens anteriores, 'Cartoons' e 'Banda desenhada', também se observaram diferenças significativas entre os professores portugueses e espanhóis, sendo os portugueses a apresentarem uma média de concordância superior.

\subsection{O uso do humor no ensino da Matemática}

É comumente aceite a influência das estratégias de ensino que os professores experienciaram enquanto alunos nas suas práticas letivas subsequentes. Partindo deste pressuposto, desafiamos os professores a fazer um exercício de memória para recordarem momentos de humor na sala de aula por parte dos seus professores de Matemática. Tal exercício não despertou qualquer recordação por parte da maioria dos professores $(61,3 \%)$. Entre os que recordaram, um pouco mais de um terço da amostra, e que responderam a questão seguinte “Com que finalidade era usado o humor pelos seus professores de Matemática?”, destacaram as finalidades 'Motivar', com maior prevalência para os professores do EP e do ES, 'Criar um bom ambiente', com maior destaque para os professores do EP. Estes professores também se destacam na concordância do uso do humor com a finalidade de 'Fazer pensar' e de 'Ensinar conceitos' (Tabela 10).

Tabela 10 - Média da concordância dos professores e valor de $\mathrm{p}$ nos itens sobre a finalidade do humor usado pelos seus professores de Matemática, segundo o nível de ensino

\begin{tabular}{lcccc}
\hline \multirow{2}{*}{$\begin{array}{l}\text { Enquanto aluno, com que finalidade era usado o humor } \\
\text { pelos seus professores de Matemática }\end{array}$} & \multicolumn{4}{c}{ Média segundo o nível de ensino } \\
\cline { 2 - 4 } Valor de p \\
\hline Criar bom ambiente & 3,50 & 3,41 & 3,42 & 0,523 \\
Motivar & 3,56 & 3,25 & 3,52 & $0,000^{*}$ \\
Fazer pensar & 3,35 & 3,04 & 2,85 & $0,000^{*}$ \\
Ensinar conceitos & 3,08 & 2,74 & 2,48 & $0,000^{*}$ \\
\hline
\end{tabular}

"Diferenças estatisticamente significativas para $p<0,05$.

Fonte: Elaboração dos autores (2019).

Na comparação das médias dos três níveis de ensino, a análise de variância One-Way Anova determinou diferenças significativas em três dos quatro itens. No item relativo ao atributo utilizar o humor para 'Motivar' existem diferenças significativas entre os professores do EP e do EM. Nos restantes dois itens, relativos aos atributos utilizar o humor para 'Fazer pensar' e 'Ensinar conceitos', observaram-se diferenças significativas entre os professores do EP e os professores de qualquer dos outros dois níveis de ensino.

Nestes itens observaram-se diferenças significativas entre os professores portugueses e espanhóis somente no item 'Motivar', sendo os portugueses a apresentarem uma média de concordância superior. 
Finalmente, questionados sobre o uso do humor para ensinar Matemática, a maior parte dos professores $(89,4 \%)$ afirma fazê-lo algumas vezes. Os professores do EP destacam-se nas finalidades de 'Motivar', 'Fazer pensar' e 'Ensinar conceitos', enquanto os professores do EM e do ES se destacam na finalidade 'Criar um bom ambiente' (Tabela 11).

Tabela 11 - Média da concordância dos professores e valor de $\mathrm{p}$ nos itens sobre a finalidade do humor no seu ensino de Matemática, segundo o nível de ensino

\begin{tabular}{lcccc}
\hline \multirow{2}{*}{$\begin{array}{l}\text { Enquanto professor de Matemática, com que finalidade usa } \\
\text { o humor nas suas aulas }\end{array}$} & \multicolumn{3}{c}{ Média segundo o nível de ensino } & \multirow{2}{*}{ Valor de p } \\
\cline { 2 - 4 } Crimário & Médio & Superior & \\
\hline Motivar & 3,43 & 3,51 & 3,52 & 0,243 \\
Fazer pensar & 3,60 & 3,47 & 3,38 & $0,001^{*}$ \\
Ensinar conceitos & 3,32 & 3,15 & 3,26 & $0,002^{*}$ \\
\hline
\end{tabular}

${ }^{*}$ Diferenças estatisticamente significativas para $p<0,05$.

Fonte: Elaboração dos autores (2019).

Entre as médias dos três níveis de ensino, verifica-se que existem diferenças significativas em três dos quatro itens. Nos itens relativos aos atributos usar o humor com a finalidade de 'Motivar' e 'Ensinar conceitos' existem diferenças significativas entre os professores do EP e os professores de qualquer dos outros dois níveis de ensino. No outro item, relativo ao atributo usar o humor para 'Fazer pensar', observaram-se diferenças significativas entre os professores do EP e os professores do EM.

Neste caso, entre os professores portugueses e espanhóis observaram-se diferenças significativas em todos os quatro itens, obtendo-se uma média de concordância superior para os espanhóis no item 'Criar bom ambiente' e para os portugueses em todos os três restantes.

\subsection{O humor em Matemática}

Nesta subsecção analisam-se as respostas dos professores à totalidade dos itens do questionário, com exceção dos quatro itens da questão "Com que finalidade era usado o humor pelos seus professores de Matemática?". Neste itens, em que se indagavam os participantes sobre os seus antigos professores de Matemática, um elevado número de professores não respondeu por não ter essa experiência (recorde-se que só um pouco mais de um terço dos professores se recordava do uso do humor pelos seus professores de Matemática). Assim, a exclusão desses itens, não focados na própria experiência dos participantes, mas na sua visão sobre os seus professores de Matemática, permitiu aumentar consideravelmente a dimensão da amostra.

Seguidamente, estudamos, para esses itens, a consistência interna, tendo-se obtido o 
valor 0,922 para o coeficiente alfa de Cronbach. Ora, este valor muito próximo de 1, permite admitir que o questionário avalia um único constructo e, portanto, operar com o score total dos itens considerados. Tendo em conta estes pressupostos, em seguida, estuda-se o score total desses itens, segundo as variáveis nível de ensino e nacionalidade.

No caso da variável nível de ensino, apresentam-se na Tabela 12 a média e o desvio padrão de concordância e o valor de $p$ relativos ao conjunto de todos os itens considerados, segundo o nível de ensino.

Tabela 12 - Média e desvio padrão da concordância dos professores e valor de $p$ na globabilidade dos itens considerados, segundo o nível de ensino

\begin{tabular}{lccc}
\hline Nível de ensino & Média & Desvio padrão & Valor de $\mathrm{p}$ \\
\hline Primário $(n=269)$ & 149,6 & 16,21 & $0,000^{*}$ \\
Médio $(n=454)$ & 143,4 & 14,79 & \\
Superior $(n=48)$ & 143,4 & 14,28 & \\
\hline${ }^{*}$ Difecra
\end{tabular}

${ }^{*}$ Diferenças estatisticamente significativas para $p<0,05$.

Fonte: Elaboração dos autores (2019).

Pela Tabela 12, verifica-se que a média dos professores do nível primário se destaca relativamente aos professores do nível médio e do nível superior, tendo a análise de variância One-Way Anova determinado diferenças estatisticamente significativas entre as três médias. Prosseguindo com a análise a posteriori, do estudo das comparações múltiplas entre quaisquer dois grupos, o teste de Bonferroni determinou diferenças estatisticamente significativas entre os grupos primário e médio e entre os grupos primário e superior. Este resultado corrobora o maior nível de concordância média dos professores do Ensino Primário que foi verificado anteriormente em muitos itens.

No caso da variável nacionalidade, apresentam-se na Tabela 13 a média e o desvio padrão de concordância e o valor de $p$ relativos ao conjunto de todos os itens do questionário considerados, segundo a nacionalidade dos participantes.

Tabela 13 - Média e desvio padrão da concordância dos professores e valor de p na globalidade dos itens considerados, segundo a nacionalidade

\begin{tabular}{lccc}
\hline Nacionalidade & Média & Desvio padrão & Valor de $\mathrm{p}$ \\
\hline Portuguesa $(n=426)$ & 147,9 & 16,20 & $0,000^{*}$ \\
Espanhola $(n=346)$ & 142,7 & 14,16 & \\
\hline
\end{tabular}

${ }^{*}$ Diferenças estatisticamente significativas para $p<0,05$.

Fonte: Elaboração dos autores (2019).

De entre os profesores portugueses e espanhóis, conclui-se que são os professores portugueses que apresentam uma concordância média superior. Adicionalmente, verifica-se que as diferenças entre os dois grupos são estatisticamente significativas por aplicação do teste $t$ de Sudent, para amostras independentes. Tal como no caso anterior, este resultado corrobora o maior nível de confiança média dos professores portugueses que foi observado anteriormente 
em muitos itens.

\section{Conclusões}

Este estudo revela que os professores ibéricos que ensinam Matemática, desde o Ensino Primário até ao Ensino Superior, consideram que têm sentido de humor $(89,8 \%)$ e apreciam o humor, associando-o a situações que ajudam a 'aliviar a tensão/ansiedade', a 'estimular o pensamento', a 'descontrair' e a 'melhorar a autoestima'. Globalmente, são os professores do Ensino Primário que apresentam uma maior média de confiança nos diferentes atributos associados ao humor.

Os professores, de um modo geral, apreciam o sentido de humor nos outros porque os ajuda a 'sentirem-se mais à vontade e descontraídos', a 'gerir situações difíceis' e a ser 'mais produtivos no trabalho', registrando-se diferenças significativas entre os professores do Ensino Primário e os professores do Ensino Médio.

O reconhecimento do valor educativo do humor no ensino da Matemática é esmagador entre os professores (98\%), destacando-se os do Ensino Primário dos restantes quanto às razões que o justificam, como facilitar 'a relação pedagógica entre o professor e os alunos', tornar 'a Matemática mais atrativa', estimular 'o pensamento matemático' e facilitar 'a comunicação matemática'. Mais uma vez, são os professores do Ensino Primário que se destacam relativamente aos demais no seu maior grau de concordância com o recurso didático do humor.

Quanto ao uso efetivo do humor no ensino da Matemática, apenas cerca de 40\% dos professores se recorda da sua utilização por parte de um dos seus antigos professores de Matemática, servindo para 'Motivar' (com diferenças significativas entre os professores do Ensino Primário e do Ensino Médio), 'Fazer pensar' e 'Ensinar conceitos' (com diferenças significativas entre os professores do Ensino Primário e os demais). Estes usos do humor são consistentes com os encontrados em outros estudos, destacando-se em todos uma utilização do humor para o ensino explícito de conteúdos programáticos (MACHLEV; KARLIN, 2017; WANZER et al., 2006; ZIV, 1988).

Em termos do uso do humor para ensinar Matemática, uma percentagem muito elevada dos professores $(89,4 \%)$ refere fazê-lo algumas vezes. Uma vez mais, os professores do Ensino Primário destacam-se nas finalidades de 'Motivar', 'Fazer pensar' e 'Ensinar conceitos', enquanto os professores do Ensino Médio e do Ensino Superior se destacam na finalidade 'Criar um bom ambiente'.

Em síntese, estes resultados revelam que os professores que ensinam Matemática 
reconhecem o significado de humor, sentem que têm sentido de humor, encontram razões para o utilizar no ensino da Matemática e já o viram utilizar ou utilizam nas suas aulas, com a intenção de criar um bom ambiente de aprendizagem e de fazer pensar os alunos (ADÃO, 2016; BANAS et al., 2011; FLORES; MORENO, 2011; GUITART, 2012; MARTIN, 2007; WANZER et al, 2006).

As diferenças que se registram entre os professores dos diversos níveis de ensino revelam que existe uma maior predisposição dos professores do Ensino Primário, comparativamente com os demais, para valorizar e utilizar o humor no ensino da Matemática. Isso pode dever-se, por um lado, à formação que tiveram (mais formação em didática da Matemática) mas também ao nível de ensino em que lecionam (CASTRO; FLORES, 2012). Conjectura-se que o crescente nível de formalização da Matemática, à medida que se avança no nível de escolaridade, deixa cada vez menos espaço ao humor. Ainda assim, sublinha-se os elevados valores em termos de valorização e utilização no ensino da disciplina em todos os níveis de ensino. Adicionalmente, o estudo revela também diferenças entre professores portugueses e professores espanhóis. Estas diferenças talvez aconteçam devido às alterações curriculares que se verificaram em Portugal no início da década de 2010 e aos programas nacionais de formação contínua de professores, da mesma época, que vieram valorizar o ensino exploratório da Matemática, assente em tarefas matemática desafiantes e contextualizadas no quotidiano, incorporando, muitas delas, ambientes lúdicos.

\section{Referências}

ADÃO, T. Os processos cognitivos subjacentes à apreciação do humor: Contributos para o professor/mediador de língua materna-português. 2016. Tese (Doutorado em Didática das Línguas) Faculdade de Letras, Universidade do Porto, Porto, 2016.

BANAS, J. A.; DUNBAR, N;, RODRIGUEZ, D.; LIU, S. J. A review of humor in educational settings: Four decades of research. Communication Education, Thames, v. 60, n. 1, p. 115-144. 2011.

CASTRO, E.; FLORES, P. Preparing teachers of mathematics in Spain. In: SCHWILLE, J.;

INGVARSON, L.; HOLDGREVE-RESENDEZ, R. (Ed.). TEDS-M Encyclopedia: A Guide to Teacher Education context, Structure, and Quality Assurance in 17 Countries. Amsterdan: IEA Secretariat, Herengracht, 2012. p. 211-226.

DIONIGI, A.; CANESTRARI, C. The role of laughter in cognitive-behavioral therapy: case studies. Discourse Studies, v. 20, n.3, p. 323-339, 2018.

FLORES, P.; MORENO, A. J. Matemáticamente competentes para reír. Barcelona: Graó, 2011.

GALL, M. D.; GALL, J. P.; BORG, W. R. Educational research: An introduction 7. ed. Boston: A \& B Publications, 2003. 
GUERREIRO, A.; TOMÁS FERREIRA, R.: MENEZES, L.: MARTINHO, M. H. Comunicação na sala de aula: A perspetiva do ensino exploratório da matemática. Zetetiké: Revista de Educação Matemática, Campinas, v. 23, n. 4, p. 279-295, 2015.

GUITART, M. Permitido reír... Estamos en clase. El humor como recurso didáctico en aula de Estadística. 2012. Tese (Doutorado em Didática da Matemática) - Universidade Nacional de Cuyo, Mendonza, 2012.

HILL, C. E.; WILLIAMS, E. N. The sample. In: HILL, C. E. (Ed.). Consensual qualitative research: A practical resource for investigating social science phenomena. Washington: American Psychological Association, 2012. p. 71-82.

LAINESTE, L.; VOOLAID, P. Laughing across borders: Intertextuality of internet memes. European Journal of Humour Research, v. 4, n. 4, p. 26-49, 2016.

LOVORN, M.; HOLAWAY, C. Teachers' perceptions of humour as a classroom teaching, interaction, and management tool. The European Journal of Humour Research, v. 3, n. 4, p. 24-35, 2015.

MACHLEV, M.; KARLIN, N. J. The Relationship Between Instructor Use of Different Types of Humor and Student Interest in Course Material. College Teaching, v. 65, n. 4, p. 192-200, 2017.

MARTIN, R. The Psychology of Humor - An Integrative Approach. London: Elsevier Academic Press, 2007.

MARTINS, A. I. A seriedade do Humor ao longo dos séculos: uma retórica do poder político ou de um contra-poder? Revista Iberoamericana de Estudios de Desarrollo, v. 4, n. 1, p. 323-346, 2015.

MATARAZZO, K. L.; DURIK, A. M.; DELANEY, M. L. The effect of humorous instructional materials on interest in a math task. Motivation and emotion, v. 34, n. 3, p. 293-305, 2010.

MEYER, J. C. Understanding Humor Through Communication: Why be Funny, Anyway? Lanham: Lexington Books, 2015.

NCTM. Cartoon Corner: Humor-Based Mathematics Activities, Reston: National Council of Teachers of Mathematics, 2007.

NCTM. Cartoon Corner 2: Humor-Based Mathematics Activities, Reston: National Council of Teachers of Mathematics, 2013.

PESTANA, M. H.; GAGEIRO, J. N. Análise de dados para ciências sociais: A complementaridade do SPSS. Lisboa: Edições Sílabo, 2008.

PORTUGAL. Ministério da Educação e Ciência. Lei n ${ }^{0} 79$, de 14 de maio de 2014. Aprova o regime jurídico da habilitação profissional para a docência na educação pré-escolar e nos ensinos básico e secundário. 2014. Disponível em: https://dre.pt/pesquisa/-/search/25344769/details/maximized. Acesso em: 12 mar. 2020.

RODRIGUES, R.; CYRINO, M.; OLIVEIRA, H. Comunicação no Ensino Exploratório: visão profissional de futuros professores de Matemática. Bolema, Rio Claro, v. 32, n. 62, p. 967-989, 2018.

SHMAKOV, P.; HANNULA, M. S. Humour as means to make mathematics enjoyable. In: SIXTH CONGRESS OF THE EUROPEAN SOCIETY FOR RESEARCH IN MATHEMATICS EDUCATION, 1., 2009, Lyon (France), Proceedings. Lyon: CERME, 2010. p. 144-153.

TOH, T. L.; CHENG, L. P.; HO, S. Y.; JIANG, H.; LIM, K. M. Use of comics to enhance students' 
learning for the development of the twenty-first century competencies in the mathematics classroom. Asia Pacific Journal of Education, v. 37, n. 4, p. 437-452, 2017.

WANZER, M.: BAINBRIDGE FRYMIER, A.; WOJTASZCZYK, A. M.; SMITH, T. Appropriate and inappropriate uses of humor by teachers. Communication Education, Thames, v. 55, n. 2, p. 178196, 2006.

ZIV, A. Teaching and learning with humor: Experiment and replication. The Journal of Experimental Educational, v. 57, n. p. 5-15, 1988. 